\title{
Konflik Kekerasan antar Anggota Kelompok Beladiri dalam Paradigma Sosiologi Olahraga (Kajian Kepemimpinan)
}

\author{
Harwanto \\ University of PGRI Adi Buana, Jl. Menanggal, Surabaya 60245, Indonesia
}

"Corresponding author: harwanto@unipasby.ac.id

\author{
ARTICLE INFO \\ Article history: \\ Received 21 August 2017 \\ Received in revised form 28 Sept 2017 \\ Accepted 10 Oct 2017
}

Keywords:

Behavior, pencak silat, social, sport

\begin{abstract}
A B S T R A C T
Actualization of violent conflict is seen as a social phenomenon for expressing oneself in aggressive behavior. However, this behavior is basically a process of social learning how to train members about the skills, traits, values, attitudes, norms and knowledge associated with the role in the sport. Given the breadth of issues examined in the perspective of the sociology of sport, the researchers limit the problem focused on the study of organizational leadership in the martial arts is still vulnerable to conflict among group members. Reality data sources will be described and analyzed to build a proposition. This research is a form of case study, which focused on social phenomenon of violent conflict that often happened to members of organization group especially martial arts Pencak Silat. The cases of violent conflict are examined through a qualitative method approach, so that the study of problems and the application of research methods becomes an argumentative choice. The conclusion that violent conflict that has been happening because it is influenced by the leadership that still put forward the approach of humanist pattern and organizational prestige. It is based on findings about the value of understanding the teachings of Pencak silat members is not maximized and the transformation of Pencak Silat as a cultural value to sports that are not completed. Built proposition is that strong solidarity will build ingroup-outgroup group, a strong solidarity built through routine activities, social solidarity that is built is both functional and dysfunctional. Functional properties strengthens group solidarity while dysfunctional cause attitude deglorification member, Attitude deglorification is used by some members to private interests so expand conflicts and continue prolonged, violent conflict continuously also caused by not optimal understanding of the value of the teachings of martial arts and not complete cultural transformation to the branch sports, not complete cultural transformation to the sport led to the organization Pencak silat more closely with community organizations, while the community organization much coincide with the political, economic and social (in politics: community organization into a source of power, economically: the organization of society into a source of revenue, in Social: they build social solidarity to maintain its existence).
\end{abstract}

\section{Pendahuluan}

Berkembang tidaknya sebuah organisasi tergantung dari kemampuan seorang pemimpin dalam mengelola perusahaannya, sekalipun usaha itu bergerak dalam bidang sumber daya manusia atau organisasi beladiri. Ini menunjukkan bahwa pemimpin memunyai peran yang sangat penting dalam mencapai tujuan dan keberhasilan. Kepemimpinan merupakan kemampuan seorang pemimpin memengaruhi orang lain/ bawahan untuk mencapai tujuan bersama baik dalam organisasi maupun institusi kelembagaan.

Berbagai rumusan tentang definisi kepemimpinan menurut para ahli sebagai berikut:

Fiedler (1967) menyatakan bahwa kepemimpinan pada dasarnya merupakan pola hubungan antara individu-individu yang menggunakan wewenang dan pengaruhnya terhadap kelompok orang agar bekerja bersama-sama untuk mencapai tujuan. Sementara menurut Pfiffner, kepemimpinan adalah kemampuan mengkoordinasikan dan memotivasi orang-orang dan kelompok untuk mencapai tujuan yang di kehendaki. Davis (1977), mendefinisikan kepemimpinan adalah kemampuan untuk mengajak orang lain mencapai tujuan yang sudah ditentukan dengan penuh semangat. Sedangkan Ott (1996) menyatakan bahwa kepemimpinan dapat didefinisikan sebagai proses hubungan antar pribadi yang di dalamnya seseorang mempengaruhi sikap, kepercayaan, dan khususnya perilaku orang lain. Locke et.al. (1991), mendefinisikan kepemimpinan merupakan proses membujuk orang lain untuk mengambil langkah menuju suatu sasaran bersama Kelima definisi tersebut, memiliki tinjauan dari sudut pandang yang berbeda yakni pola hubungan, kemampuan mengkoordinasi, memotivasi, kemampuan mengajak, membujuk dan mempengaruhi orang lain.

Sudut pandang tersebut jika dikaitkan dengan permasalahan dalam penelitian sebenarnya secara teoritis bertentangan dengan apa yang terjadi di lapangan. Mengingat berbagai kasus yang muncul lebih cenderung pada terjadinya konflik antar kelompok anggota organisasi beladiri. Sedangkan dalam kajian teoritis lebih mengedepankan pada nilainilai perubahan positif, seperti membangun kebersamaan, menjalin harmonisasi keanggotaan dan berupaya meningkatkan produktivitas. Sedangkan konflik dalam sebuah organisasi tentu tidak bisa dihindarkan dan akan selalu hadir selama proses kehidupan dan perkembangannya, sebagaimana kasus konflik kekerasan yang terjadi pada Organisasi beladiri pencak silat. Menurut Marx (1956) menyebutkan bahwa, "...without conflict, no progress; that is the law which is cilivization has followed the present day", tanpa konflik, tidak ada perkembangan; itu adalah hukum pada peradaban sampai sekarang. Itu artinya bahwa konflik memiliki nilai fungsional, jika dipandang sebagai bentuk kompetisi dan mampu mengelola dengan baik untuk menjadi sebuah perubahan. Namun konflik 
juga bersifat disfungsional jika memerkuat rasa permusuhan (hostile feeling), muncul sikap kekecewaan (deprivation), menanamkan rasa balas dendam atas pengalaman konflik masa lalu (vengeance) hingga terjadinya akumulasi rasa kebencian yang terus sengaja menciptakan konflik berkepanjangan.

Konflik yang dimaksud dalam penelitian ini lebih bermuara pada bentuk persaingan antar kelompok organisasi yang dilakukan oleh anggota yang tidak bertanggungjawab. Sebagaimana pernyataan dari beberapa informan yang mengatakan bahwa konflik dipicu oleh oknum anggota yang tidak bertanggungjawab. Kata oknum yang tidak bertanggungjawab berarti sebagian dari anggota yang telah melakukan pelanggaran dari ketentuan yang tidak dikehendaki oleh organisasi. Sedangkan sumber konflik sering dilakukan oleh kelompok komunitas dari anggota masing-masing organisasi yang sengaja diciptakan sebagai bentuk persoalan pribadi. Kasus konflik kekerasan yang telah berlangsung selama ini menyisakan keprihatinan yang mendalam, khususnya bagi masyarakat umum. Konflik yang terjadi tersebut sering mengarah kepada tindakan kekerasan hingga melibatkan massa, bahkan tidak sedikit kerugian yang dirasakan oleh berbagai pihak, termasuk masyarakat yang tidak ikut terlibat konflik turut menjadi sasaran amukan massa. Kondisi yang demikian dianggapnya sebagai sesuatu yang wajar dan seakan telah menjadi budaya bagi mereka. Dianggap sebagai budaya karena kasus ini terjadi terus berulang-ulang, hal ini mengindikasikan adanya kelompok komunitas tertentu yang sengaja menciptakan konflik, walaupun bertentangan dengan tujuan organisasi.

Secara empirik aktualisasi konflik kekerasan dipandang sebagai fenomena sosial untuk mengekspresikan diri dalam perilaku agresif. Perilaku ini pada dasarnya merupakan proses pembelajaran keterampilan, sifat-sifat, nilai, sikap, norma dan pengetahuan yang dikaitkan dengan peranan dalam olahraga (De Knop, 1996). Mengingat begitu kompleks dan luasnya permasalahan yang dikaji dalam perspektif sosiologi olahraga, maka peneliti membatasi pemasalahan yang difokuskan pada kajian kepemimpinan dalam organisasi beladiri yang masih rentan dengan terjadinya konflik antar kelompok anggotanya. Realita sumber data nantinya akan didiskripsikan dan dianalisis untuk membangun sebuah proposisi.

\section{Metode Penelitian}

Penelitian ini merupakan bentuk studi kasus, yang difokuskan pada fenomena sosial tentang konflik kekerasan yang sering terjadi pada anggota kelompok organisasi khususnya beladiri Pencak silat. Kasus konflik kekerasan tersebut diteliti melalui pendekatan metode kualitatif, sehingga kajian permasalahan dan penerapan metode penelitiannya menjadi pilihan yang argumentatif.

Penelitian kualitatif ini dimaksudkan untuk membangun pengetahuan melalui pemahaman dan penemuan (meaning and discovery), sehingga dalam proses penggalian data penelitian di lapangan dilakukan penalaran secara induktif dan dialektik. Hal ini dilakukan sebagai kontrol dalam kerangka mengidentifikasi dan membatasi masalah (identification and limit the problem) yang diteliti.

Penelitian ini menggunakan observasi terstruktur dan tidak terstruktur serta interaksi komunikatif sebagai alat mengumpulkan data, terutama dalam wawancara secara mendalam (indepth interview) dan status peneliti menjadi instrumen utamanya. Sedangkan data bersifat subyektif, karena melibatkan persepsi dan keyakinan (perception and beliefes) peneliti dan subyek. Sedangkan data penelitian berbentuk pernyataan katakata, narasi maupun dokumen yang relevan. Data dianalisis dalam terminologi respons-respons individual secara diskriptif. Selanjutnya data diidentifikasi sesuai kategori untuk menyortir dan mengorganisasikan data (sorting and organizing data).

Danim, S. (2002) menyebutkan beberapa ciri dalam penelitian kualitatif sebagai berikut: 1 . sumber data langsung berupa tata situasi alami dan peneliti adalah instrumen kunci, 2. Bersifat diskriptif, 3. Lebih menekankan makna proses dari pada hasil, 4. Analisis data bersifat induktif, dan 5. Makna merupakan perhatian utama dalam pendekatan penelitian.

Dasar teoritis dalam penelitian ini adalah membentuk makna (meaning) dan diskripsi lain yang berhubungan dengan alasan mengapa konflik kekerasan terus berkepanjangan, sehingga akan menentukan paradigma yang memberikan orientasi tentang cara berpikir peneliti dan bagaimana penelitian ini akan dilakukan.

Dalam metode penelitian studi kasus ini, penelaahan berbagai sumber data dibutuhkan dengan berbagai macam instrumen pengumpulan data mulai dari wawancara mendalam, observasi partisipan, dokumentasidokumentasi dan ragamnya instrumen yang digunakan, dengan demikian akan membuat lengkapnya data secara komprehensif. Hal tersebut dimaksudkan agar diperoleh data yang representative, sehingga diharapkan dapat memeroleh konsep-konsep metode dan analisis secara holistik dengan tujuan memertahankan keutuhan atau wholeness dari objek. Keutuhan yang dimaksud adalah faktualisasi data secara empiris, peran obyektivitas peneliti dalam memerlakukan informan kedua anggota organisasi, analisis data yang dilakukan melalui tahapan mereduksi data (data reduction), menampilkan/mengeksplorasi data (data display), dan memilih/ menentukan data penelitian (conclusion drawing/verification).

\section{Simpulan}

Berdasar hasil pembahasan analisis data dan temuan penelitian di lapangan, maka sesuai dengan rumusan masalah dapat disimpulkan sebagai berikut bahwa konflik kekerasan yang selama ini terjadi karena dipengaruhi oleh pola kepemimpinan yang masih mengedepankan pada nilai prestise organisasi. Hal ini didasarkan pada temuan tentang pemahaman nilai ajaran Pencak silat oleh siswa/anggota yang belum maksimal dan transformasi nilai Pencak silat sebagai budaya ke cabang olahraga yang tidak tuntas. Ketidakmaksimalan pemahaman nilai ajaran akan memunculkan perilaku yang berlebihan, sedangkan perilaku yang berlebihan cenderung membangun batasan kelompok (ingroup-outgroup) jika didukung oleh solidaritas kelompok yang kuat, sehingga hal ini akan menimbulkan sikap deglorifikasi (deglorification). Sikap deglorifikasi merupakan perasaan bangga menjadi anggota organisasi yang memiliki nama besar, sekaligus berlindung dan mendapatkan perlindungan di dalamnya karena merasa mendapatkan dukungan dari solidaritas kelompoknya.

Sedangkan pemahaman nilai ajaran yang belum maksimal tersebut ditandai dengan beberapa indikator perilaku sebagai berikut:

1) adanya sikap fanatisme anggota terhadap nilai persaudaraan dalam simbol organisasi sebagai bentuk penafsiran nilai yang berlebihan. 
2) adanya aktivitas konflik yang terjadi secara terus menerus, bersifat massif dan mengarah kepada tindakan kekerasan.

3) munculnya sikap diskursif pada kelompok lain sebagai bentuk ketidakpuasan dari pengalaman konflik sebelumnya.

4) munculnya kelompok komunitas yang sengaja menciptakan dan memancing suasana konfliktual, selalu bersikap provokatif, dan bikin ulah di setiap ada peluang dan kesempatan.

5) adanya batasan kelompok (ingroup-outgroup) yang dibangun oleh solidaritas yang kuat dan cenderung berperilaku agresif dan destruktif.

Sedangkan ketidaktuntasan transfer nilai budaya ke cabang olahraga didasarkan pada munculnya sikap solidaritas kelompok anggota organisasi yang sangat kuat. Kekuatan solidaritas kelompok akan berpengaruh pada munculnya sikap deglorifikasi. Sikap ini cenderung melakukan tindakan berlebihan yang mengarah pada tindakan provokatif dan diskursif. Tindakan anggota yang berlebihan dan tidak adanya sanksi hukum yang tegas dari organisasi, maka akan cenderung menciptakan konflik kekerasan secara berulang-ulang, terus menerus dan berkepanjangan.

\section{Saran dan Rekomendasi}

Berdasarkan simpulan dan proposisi yang dibangun, maka ada beberapa hal yang perlu disarankan yakni:

1) Secara organisasi, perlu pengembangan sistem pengelolaan organisasi baik dalam penataan manajemen administratif maupun manajemen konflik.

Manajemen administratif setidaknya menata sistem dalam organisasi, yakni didasarkan atas ketegasan pada aturan dan ketentuan yang telah ditetapkan oleh pusat, seperti adanya sanksi hukum dari organisasi, batasan tegas tentang usia calon anggota, proses pelatihan yang proporsional, ketentuan pelatih yang profesional, pola kepelatihan yang lebih sistematis, maksimalisasi konstruksi nilai ajaran ke-SH-an dan membangun hubungan harmonis kepada sesama organisasi beladiri maupun pemerintahan, serta menekankan pengembangan kualitas ajaran ke arah prestasi cabang olahraga.

Sedangkan yang berhubungan dengan manajemen konflik, yakni bagaimana menyikapi konflik yang telah berlangsung selama ini menjadi sebuah motivasi menuju perubahan. Perubahan dimaksud meliputi peningkatan kualitas sumber daya anggota, yaitu melalui peningkatan kemampuan penguasaan beladiri menuju prestasi olahraga dan pemahaman nilai ajaran ke-SH-an agar terbangun karakter berbudi pekerti luhur.

2) Secara akademik, kasus konflik antar kelompok organisasi beladiri pencak silat di Madiun memunyai nilai kajian secara interdisipliner, sehingga perlu menindaklanjuti untuk dilakukan penelitian selanjutnya tentang: a) pengkajian sejarah beladiri pencak silat Persaudaraan Setia Hati secara utuh dan bersifat original, mengingat organisasi tersebut telah berkembang menjadi beberapa aliran organisasi di Indonesia, b) pengkajian konflik kekerasan antar anggota kelompok organisasi beladiri pencak silat di Madiun dalam perspektif sejarah dan budaya masyarakat Madiun, c) pengkajian konflik kekerasan antar kelompok organisasi beladiri pencak silat sebagai ranah kepastian hukum, d) pengkajian organisasi beladiri pencak silat sebagai kepentingan muatan kekuatan politik, dan e) pengkajian organisasi beladiri pencak silat sebagai ruang investasi modal ekonomi.

Berdasarkan hasil penelitian ini maka peneliti merekomendasikan beberapa konsep pemikiran sesuai dengan fakta penelitian sebagai berikut: Secara organisasi

a. bahwa dalam kerangka untuk meminimalisir konflik berkepanjangan, hendaknya pimpinan organisasi dalam peran mobilisasinya dapat menjadi figur dan simbol kedamaian dengan cara memaksimalkan pemahaman simbol persaudaraan secara benar, kharismatik, sederhana dan memayu hayuning bawana yaitu berusaha menjaga kelestarian dan kedamaian dalam dunia beladiri persilatan.

b. bahwa para pimpinan organisasi hendaknya perlu sepakat pemikiran untuk kembali ke tujuan kausa prima ilmu Setia Hati sejati, yang bertujuan membangun karakter berbudi pekerti luhur, sebagai figur perilaku dalam bermasyarakat, dan memahami nilai-nilai ajaran Setia Hati secara benar, yakni sebagai anggota organisasi:

1). mengerti keberadaan diri sendiri (ngerti jejering kapribaden),

2). mengerti keberadaan orang lain (ngerti jejering ngaurip),

3). mengerti pada keberadaan Tuhan (ngerti punjering manembah),

4). mengerti jalan menuju kematian (ngerti dununge pati)

c. bahwa antar pimpinan organisasi perlu sepakat untuk mengakhiri konflik yang selama ini terjadi menjadikan sebagai titik awal untuk membuat suatu perubahan positif ke arah prestasi cabang olahraga.

d. bahwa perlu dibangun kebersamaan untuk menyikapi masing-masing anggota yang masih melanggar ketentuan, yang telah disepakati dengan memberi kepastian sanksi hukum administratif dari masingmasing organisasinya.

e. bahwa perlu dibuat agenda kegiatan sosial oleh pemerintah kota dan kabupaten yang melibatkan semua pihak organisasi beladiri pencak silat di Madiun yang tergabung dalam IPSI, sebagai bentuk ajang silahturrahmi secara rutin, bentuk kebersamaan, sekaligus sebagai fungsi kontrol, evaluasi dan sosialisasi kepada anggota.

f. bahwa perlu dilakukan pelatihan pelatih secara profesional dan bersertifikasi dalam kerangka meningkatkan kemampuan seni dan beladiri dalam cabang olahraga prestasi. Hal ini bertujuan untuk membangun kebersamaan melalui aktivitas yang dilakukan

Secara kompetitif.

bahwa perlu agenda pertemuan antar pimpinan organisasi sebagai wahana membangun mindset anggota sebagai bentuk rasa persaudaraan, persatuan dan kebersamaan.

\section{Daftar Pustaka}

Abdalla, Arm. 2002. Say Peace: Conflict Resolution Training Manual for Muslim Communities. Virginia, USA: The Graduate School of Islamic and Social Sciences.

Aldag, R. J \& Stearns, T. M., (1987), Management. Cincinati: SouthWestern Publishing Co.

Ateng Abdulkadir, 2003. Olahraga di Sekolah. Dalam Perkembangan Olahraga Terkini Kajian Para Pakar. Juni 2003. PT. Raja Grafindo Persada. Jakarta 
Bartos dan Wehr, 2003. Using Conflict Theory. New York : Cambridge University Press

Bolton, R., (2000), People Skills: How to assert yourself listen to others, and resolve conflict. Australia: Simon \& Schuster.

Budiatin Yasmu., (2008) Proses Sosial dalam Organisasi Olahraga; Studi tentang cabang Olahraga Individu dan Cabang Olahraga Beregu di Kota Ambon. Tesis; tidak dipublikasikan. PPS Sosiologi Universitas Pattimura Ambon.

Chandra, R. I. 1992. Konflik dalam hidup sehari-hari. Yogyakarta: Penerbit kausius.

Coser, L. 1967. The Functions of Social Conflict. Il. Free Press, Glencoe, dari www.2.pfeiffer.edu/-iridiner/courses/Oser 1 HTML diakses pada 22-12-2008

Dahrendorf, R. 1959. Class and Class Conflict in Industrial Society. California: Standford University Press.

De Knop, Paul 1996. Sport for All. Dalam Current Issues of Sport Sciences Schoondorf: Vrelag Karl Herman

DuBrin, A.J., 1984. Foundations of Organizational Behavior An Applied Perspective. London: Prentice-Hall International, Inc.

Edelmann, R. J., (1993), Interpersonal Conflicts at Work. London: BPS (The British Psychological Society).

Galtung, J. 1990. The Violence of Culture. Journal of Peace Research, vol.27. No. 3. IqYo, pp.291-305, diakses di http://www.jstor.org/about/terms.html.

Galtung, Johan. 1975. Violence, Peace, and Peace Research. Copenhagen: christian Ejlers.

George Simmel, 1903. The sociology of Conflict : I (American Journal of Sociology.

Gibson, J. L., Invancevich, J. M., dan Donnelly, Jr. J. H., (1996), Organisasi: Perilaku, Struktur dan Proses. (Edisi kedelapan), Alih Bahasa: Nunuk Ardiani, Jakarta: Binarupa Aksara.

Giulinotti, R., Bonney, N, \& Hepworth, M. 1994. Foothball, Violence, and Social Indentity. New York: Routledge.

Greenhalgh, L., 1999. "Menangani Konflik". Dalam A.Dale Timpe, (Ed.), Memimpin Manusia. Alih bahasa oleh Sofyan Cikmat. Jakarta: PT.Gramedia.

Hendrikks, W., 1992. Bagaimana Mengelola Konflik. Diterjemahkan oleh: Arif Santoso. Jakarta: Bumi Aksara.

Henry Tajfel, 1982 dalam Maksum 2008. Psikologi Olahraga. Surabaya: Unesa University Press

Hewstone, M. \& Cairns, E., 2006. Social Psychology and Intergroup conflict. Available in http://www.ripon. Edu/ academics/ psychology. Hewstone. Htm.

Hoffer, Eric 1988. Gerakan Massa. Terjemahan Masri Maris. Jakarta: Yayasan Obor Indonesia

Maksum, A, 2007. Konflik Kekerasan antar Kelompok Perguruan Pencak Silat. Studi kasus di Daerah madiun.Penelitian fundammental

Marx, K. \& Engels, F., 2000. Manifesto of the Communist Party. Diakses $12 \quad$ April 2009 http://www.marxists.org/archive/marx/work/1848/communistanifesto/ch01.htm

Nalapraya, E.M., 1989. Sejarah Perkembangan Pencak Silat di Indonesia. Surabaya: Seminar Sehari Pencak Silat Indonesia menuju Era Organisasi Profesional.

Nasution., (1988) Metode Naturalistik Kualitatif, Bandung. Tarsito

Poloma, M.,1994, Sosiologi Kontemporer, Jakarta: PT Raja Grafindo Persada \& Yayasan Solidaritas Gadjah Mada.

Pruitt, Dean G., and Hee Kim, Sung, 2004. Social Conflict: Escalation, Stalemate, and Stattlement (3 rd Edition). New York: McGrawHill

Randall, C., 1975, Conflict Sociology: Toward and Explanatory Science, Academic Press.

Robbins, S. P, dan Coulter, M., (1999), Management. (Sixth Editions), Englewood Cliffs: Prentice Hall, Inc.

Robbins, S. P., (1990), Organization Theory: Structure, Design and Applications. Englewood Cliffs: Prentice-Hall, Inc.

Rule, James B. 1988. Theories of Civil Violence. London: University of California Press.

Sugiyono., (2004) Memahami Penelitian Kualitatif. (Cetakan ke 4), Bandung. Penerbit CV. Alfabeta

Susan, N., 2009. Sosiologi Konflik. Isu-Isu Konflik Kontemporer: edisi 1 Cetakan ke-1 Jakarta: Kencana Prenada Media group.

Tennenbaum, G., Steward, E. Singer, R.N., \& Duda, J. 1997. Position statment on agression and violence in sport: An ISSP Position Stand. http://www.issponline.org/

Wahyudi, 2008. Manajemen Konflik dalam organisasi. Jakarta: Alfabeta, CV. Anggota Ikatan Penerbit Indonesia,

Weber, M. (1963). The Sociology of Religion, translated by E. Fischoff, Beacon Press, Prentice-Hall International Editions.

Weiss, D. H., (1993), Conflict Resolution. New York: American Management Association.

Winardi (2007), Manajemen Konflik (Konflik Perubahan dan Pengembangan), Bandung, Mandar Maju. 